\title{
Supplementary material for "A global model-measurement evaluation of particle light scattering coefficients at elevated relative humidity"
}

Burgos et al.

- Figure S1 shows the location of the in situ measurement sites used in this study. The site ID has been color-coded by site type following the description used throughout the manuscript: blue for Arctic sites (BRW and ZEP), cyan for marine (CBG, GRW, GSN, MHD, PVC, PYE, and THD), dark green for mountain (JFJ), light green for rural (APP, CES, FKB, HLM, HYY, LAN, MEL, and SGP), black for urban (HFE, PGH, and UGR), and red for desert (NIM).

- Figure S2 has been added to facilitate the analysis of the results in Sect. 4.2. It shows the annual cycles of the median of $f(\mathrm{RH}=85 \% / \mathrm{RH}=40 \%)$ as measured and as predicted by two of the models (SALSA and TM5). It shows the data only for the three temporally collocated sites of Barrow, Graciosa and Southern Great Plains.

- To support the discussion in Sect. 4.3 on the importance of defining the dry reference RH, the last four figures (Figures S3, S4, S5, and S6) have been added to the supplementary material.

- Figure S3 presents the probability density function of the measured $\mathrm{RH}_{\mathrm{ref}}$ for all sites. While some sites are clearly below the recommended threshold of $\mathrm{RH}_{\text {ref }}<40 \%$, some sites clearly exceed the recommended $\mathrm{RH}$ threshold given by WMO/GAW (2016). The measurement data with $\mathrm{RH}_{\text {ref }}>40 \%$ was not considered in this study. This figure also shows the broad distribution of $\mathrm{RH}_{\text {ref }}$ at some sites, where control of the DryNeph sampling conditions was problematic.

- Figure S4 presents a closer look at the scattering enhancement of inorganic sea salt aerosol. The figure demonstrates the congruence of several independent methods for obtaining $f(\mathrm{RH})$ and is based on recent measurements of size (Salter et al., 2016), shape and hygroscopic growth of pure inorganic sea salt (Zieger et al., 2017) and Mie modeling of $f(\mathrm{RH})$ (Zieger et al., 2013). The values of $f(\mathrm{RH})$ of inorganic sea salt were modeled using the measured particle size distributions from the Stockholm sea spray simulation chamber (Salter et al., 2014), the recently revised hygroscopic growth factors $g(\mathrm{RH})$ - defined as the ratio between humidified to dry diameter - of inorganic sea salt (Zieger et al., 2017) and Mie modeling as described in Zieger et al. (2013). For the calculations, particles were assumed to be spherical, a reasonable assumption given the fact that the measured dynamic shape factor of the inorganic sea spray particles tended to be more towards spherical than cubical particles (see Fig. 1 in Zieger et al., 2017). The values of $g(\mathrm{RH})$ were taken from HTDMA measurements which were performed at eleven values of RH between 5 and $90 \%$ and for three different dry diameters $(50,100,150 \mathrm{~nm})$. The particle size 
distributions, covering a particle diameter range of approx. $14 \mathrm{~nm}$ to $10 \mu \mathrm{m}$, were taken from (Salter et al., 2015). $g(\mathrm{RH})$ below or above the smallest/largest dry diameter of the HTDMA measurements were assumed to be identical to the values of $g(\mathrm{RH})$ at the respective smallest/largest dry diameter, while they were linearly interpolated in between. The HTDMA measurements in Zieger et al. (2017) were performed for the lower (hydrating) branch of the hysteresis curve. Figure $\mathrm{S} 4$ provides further confidence in the observation of a pristine sea salt case from the Arctic (Zieger et al., 2010) using the PSI humidified nephelometer system. To illustrate the importance of the upper hysteresis branch and the efflorescence $\mathrm{RH}$ (which occurs at approximately $\mathrm{RH}=50 \%$ ), the mass growth factor measured by an electrodynamic balance (EDB) for the same sea salt is also shown (Zieger et al., 2017). If aerosols are actually on the upper branch of the hysteresis curve when they are assumed to be dry (for sea salt this could occur for $\mathrm{RH}>50 \%$ ) then the enhancement factor could be underestimated by a factor of 2 . In addition, this figure also demonstrates that even inorganic sea salt shows substantial growth at low RH (e.g. below $40 \%$ the scattering enhancement can be around 1.2).

- Figure S5 illustrates the scattering enhancement between 0 and $40 \%$ (i.e., $f(\mathrm{RH}=40 \% / \mathrm{RH}=0 \%)$ ) as calculated by the considered models.

- Figure S6 presents the probability density function of $f(\mathrm{RH}=85 \%)$ when $\mathrm{RH}_{\text {ref }}$ is set to $40 \%$ or $\mathrm{RH}_{\text {ref }}$ is taken at the driest measured RH (value between 0-40\%, see Fig. S3). 


\section{References}

Salter, M. E., Nilsson, E. D., Butcher, A., and Bilde, M.: On the seawater temperature dependence of the sea spray aerosol generated by a continuous plunging jet, J. Geophys. Res., 119, 9052-9072, https://doi.org/10.1002/2013JD021376, http://dx.doi.org/10.1002/2013JD021376, 2014.

5 Salter, M. E., Zieger, P., Acosta Navarro, J. C., Grythe, H., Kirkevåg, A., Rosati, B., Riipinen, I., and Nilsson, E. D.: An empirically derived inorganic sea spray source function incorporating sea surface temperature, Atmos. Chem. Phys., 15, 11047-11066, https://doi.org/10.5194/acp-15-11047-2015, http://www.atmos-chem-phys.net/15/11047/2015/, 2015.

Salter, M. E., Hamacher-Barth, E., Leck, C., Werner, J., Johnson, C. M., Riipinen, I., Nilsson, E. D., and Zieger, P.: Calcium enrichment in sea spray aerosol particles, Geophys. Res. Lett., 43, 8277-8285, https://doi.org/10.1002/2016GL070275, http://dx.doi.org/10.1002/ 2016GL070275, 2016GL070275, 2016.

WMO/GAW: WMO/GAW Aerosol Measurement Procedures, Guidelines and Recommendations, Report No. 227, World Meteorological Organization, Geneva, Switzerland, 2nd edition edn., 2016.

Zieger, P., Fierz-Schmidhauser, R., Gysel, M., Ström, J., Henne, S., Yttri, K., Baltensperger, U., and Weingartner, E.: Effects of relative humidity on aerosol light scattering in the Arctic, Atmos. Chem. Phys., 10, 3875-3890, https://doi.org/10.5194/acp-10-3875-2010, 2010.

15 Zieger, P., Fierz-Schmidhauser, R., Weingartner, E., and Baltensperger, U.: Effects of relative humidity on aerosol light scattering: results from different European sites, Atmos. Chem. Phys., 13, 10609-10631, https://doi.org/10.5194/acp-13-10609-2013, http://www. atmos-chem-phys.net/13/10609/2013/, 2013.

Zieger, P., Väisänen, O., Corbin, J., Partridge, D. G., Bastelberger, S., Mousavi-Fard, M., Rosati, B., Gysel, M., Krieger, U., Leck, C., Nenes, A., Riipinen, I., Virtanen, A., and Salter, M.: Revising the hygroscopicity of inorganic sea salt particles, Nat. Commun., 8, https://doi.org/10.1038/ncomms15883, 2017. 


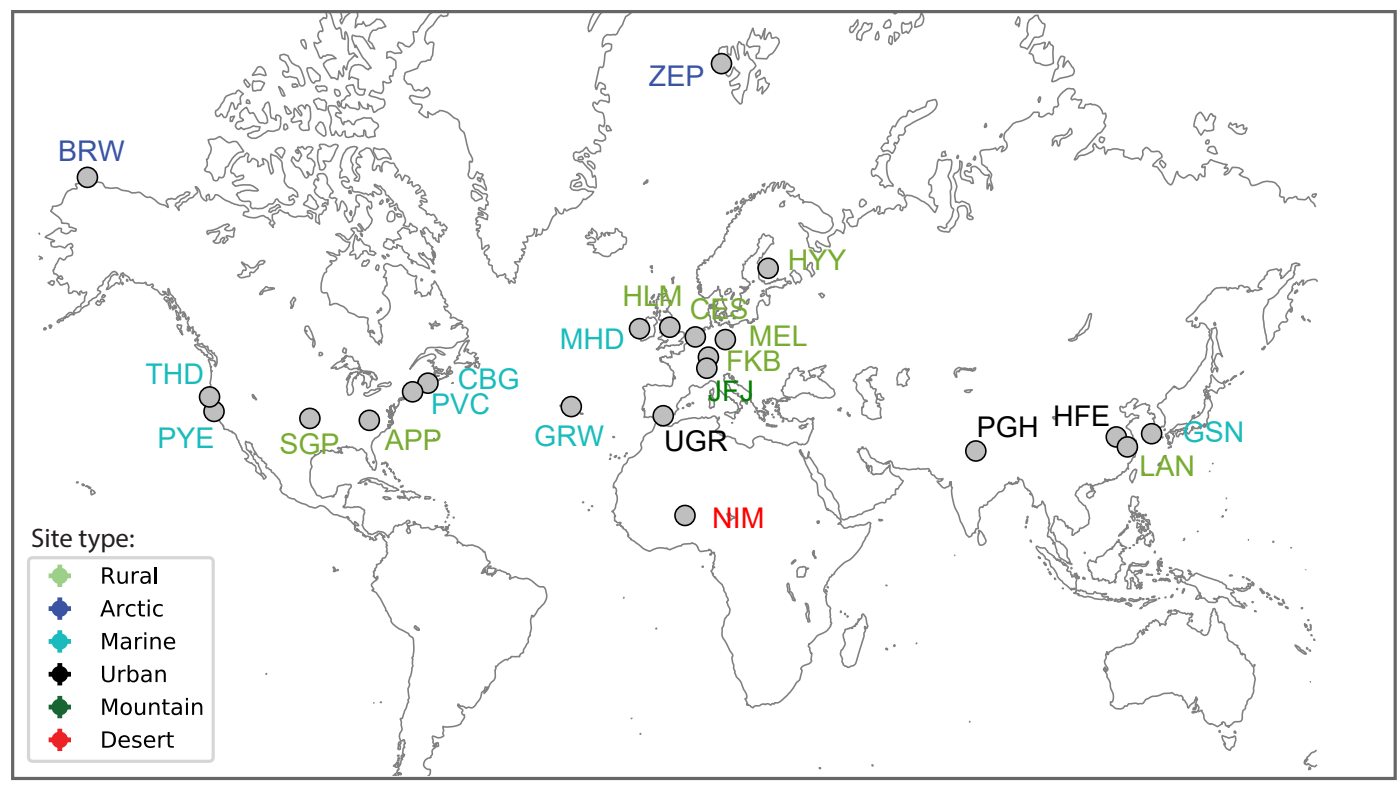

Figure S1. Location of the 22 in situ measurement sites used in this study, color-coded by site type. Station acronyms are given in Table 1 in the main manuscript. 

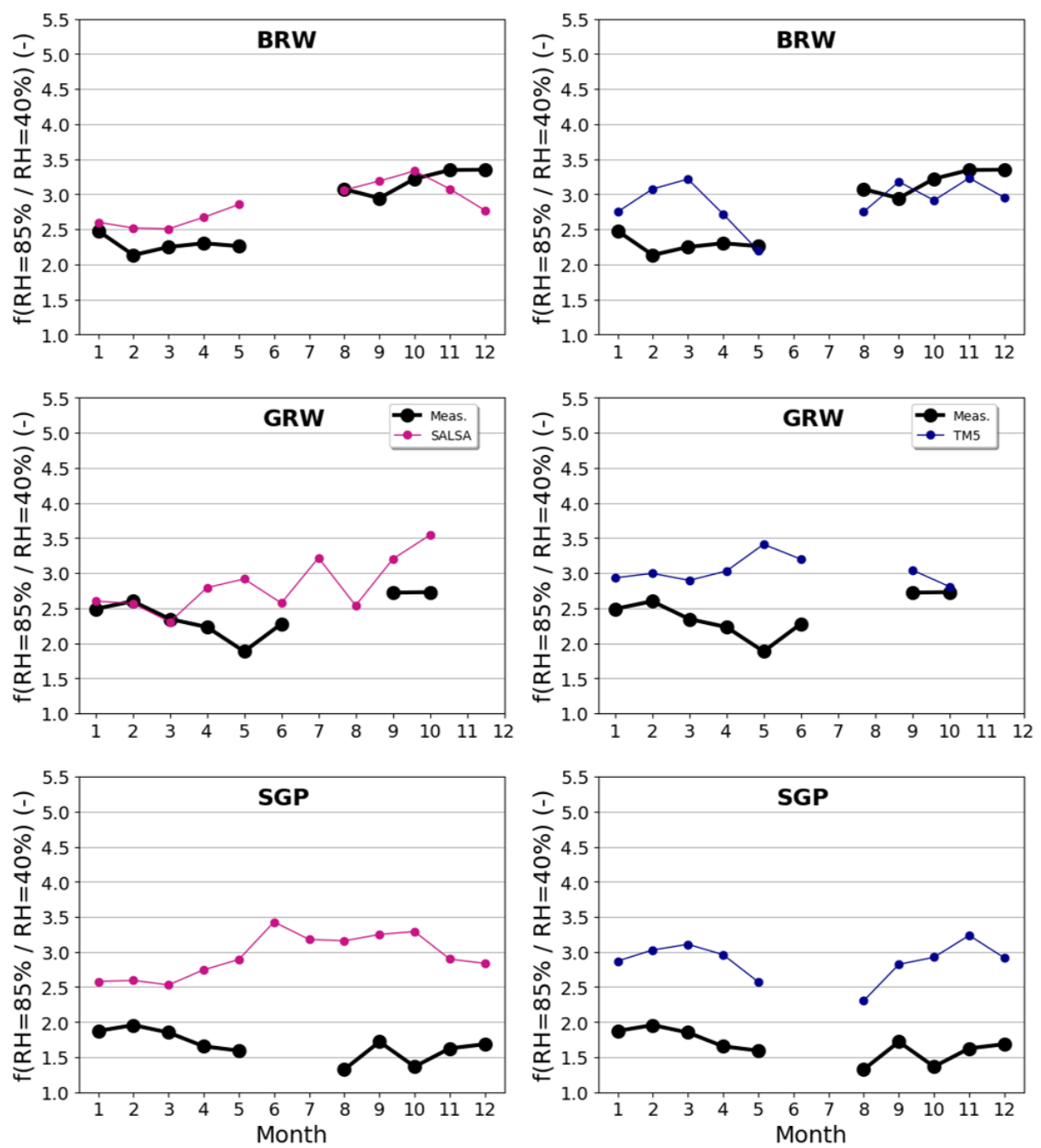

Figure S2. Annual cycles of the median $f\left(\mathrm{RH}=85 \% / \mathrm{RH}_{\mathrm{ref}}=40 \%\right)$ as measured (black line) and as predicted by the models SALSA (left panel) and TM5 (right panel) collocated for 2010: Barrow (Arctic site), Graciosa (marine site), and Southern Great Plains (rural site). 

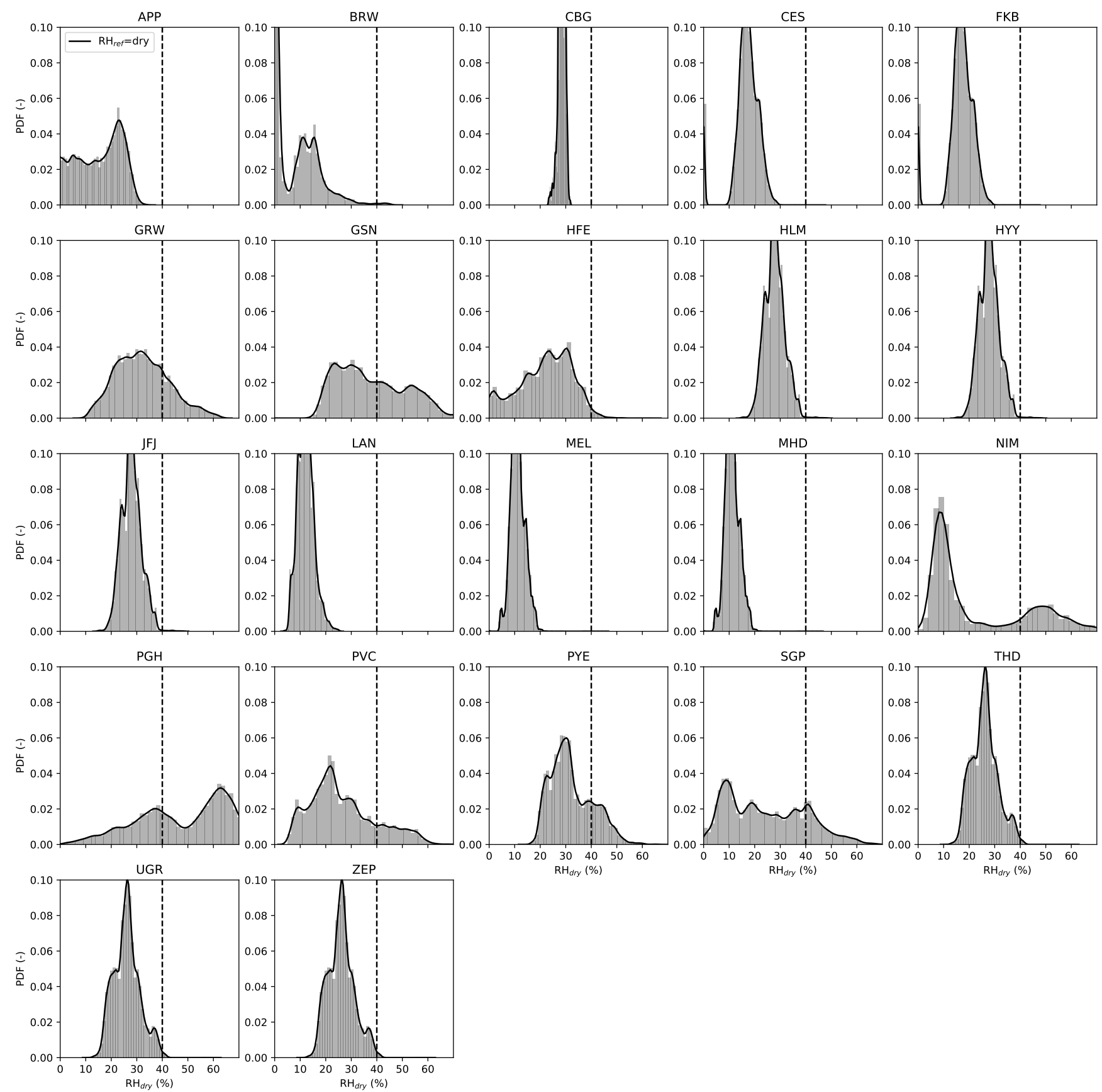

Figure S3. Probability density function of RH inside the dry nephelometer for all measurement sites used in this study. The recommended threshold for in situ sampling below $40 \%$ RH is marked by a dashed line (WMO/GAW, 2016). Station acronyms are given in Table 1 in the main manuscript. 


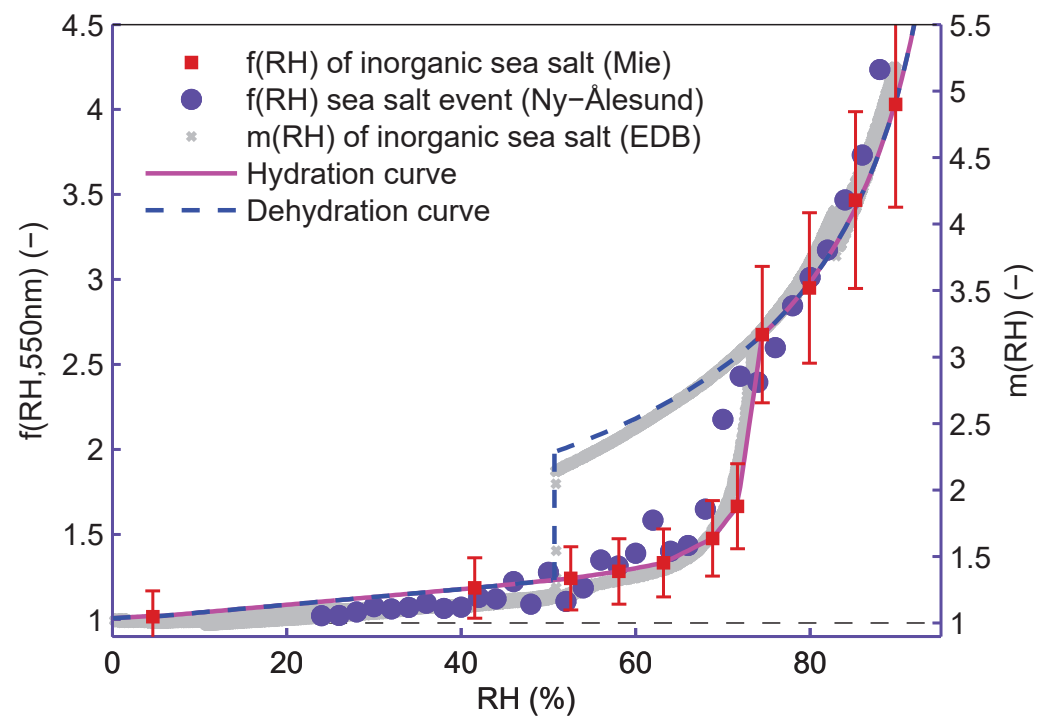

Figure S4. The scattering enhancement factor $f(\mathrm{RH})$ at $\lambda=550 \mathrm{~nm}$ of inorganic sea salt determined by several methods: (i) Mie modeling based on H-TDMA sea salt chamber measurements of Zieger et al. (2017) (red squares). Error bars denote modeling uncertainty as derived in Zieger et al. (2013). (ii) Field measurements of pristine sea salt aerosol are shown as blue symbols (Ny-Ålesund, see Zieger et al., 2010). (iii) The theoretical hydration (magenta line) and dehydration (blue dashed line) curves. Laboratory electrodynamic balance (EDB) measurements of the mass change with RH $m(\mathrm{RH})$ (gray crosses, right axis) from Zieger et al. (2017) correspond quite well with the measured and modeled $f(\mathrm{RH})$ values. 

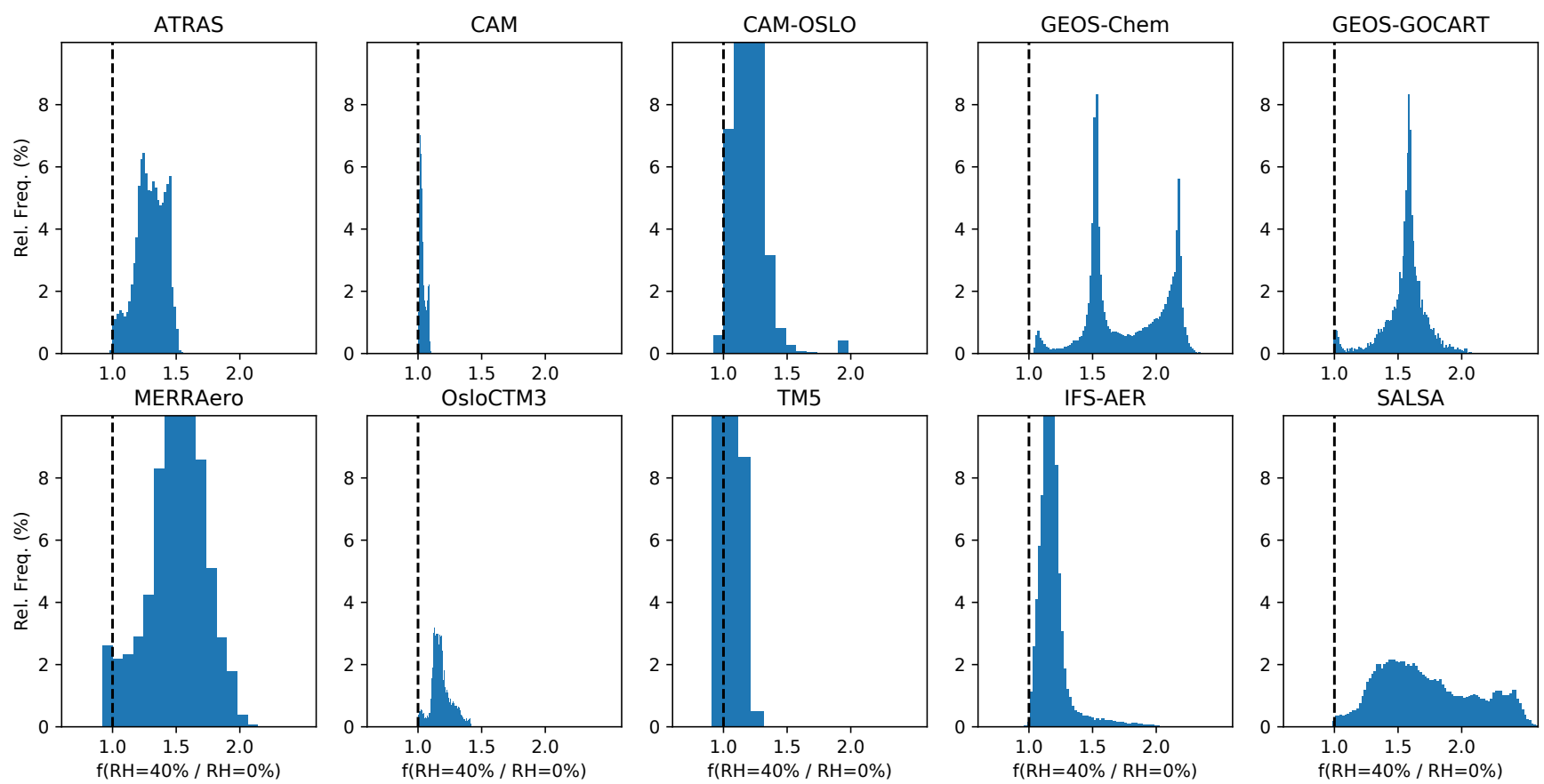

Figure S5. Relative frequency of occurrence (\%) of the modeled scattering enhancement between 0 and $40 \% \mathrm{RH}(f(\mathrm{RH}=40 \% / \mathrm{RH}=0 \%)$ calculated by the models for all sites considered in this study. The dashed black line marks the value of no change in $f(\mathrm{RH})$ between 0 and $40 \%$ RH. The y-axis for CAM-OSLO, MERRAero, TM5 and IFS-AER is kept to a maximum of 10 for illustrative purposes. 

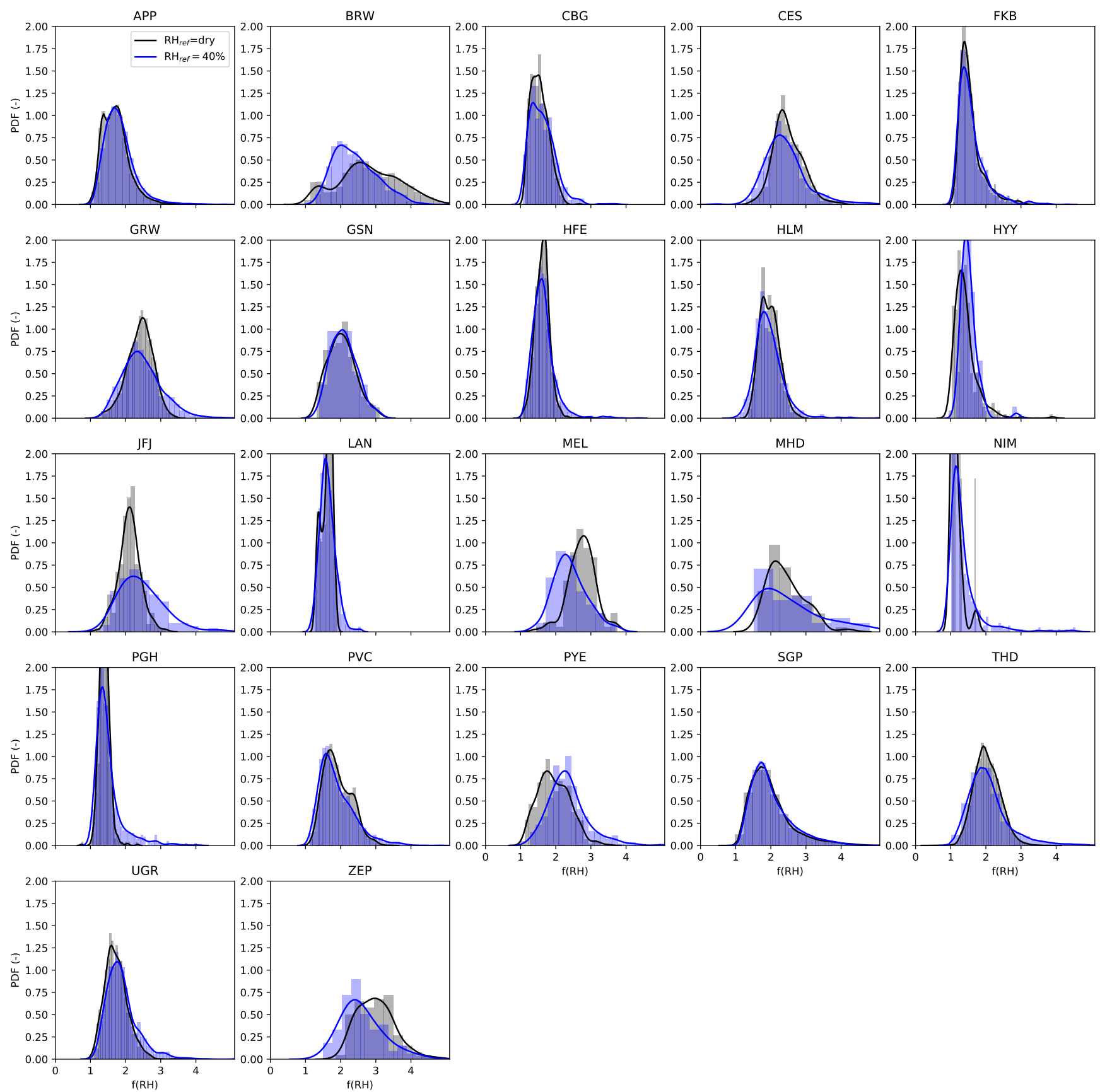

Figure S6. Probability density function of the measured $f\left(\mathrm{RH}=85 \%\right.$ ) for $\mathrm{RH}_{\text {ref }}=40 \%$ (blue) and $\mathrm{RH}_{\text {ref }}=$ dry (values below $0-40 \%$, see Fig. S3; gray) for all sites used in this study. Station acronyms are given in Table 1 in the main manuscript. 